\title{
A PRODUÇÃO DE PLOSIVAS POR CRIANÇAS DE TRÊS ANOS FALANTES DO PORTUGUÊS BRASILEIRO
}

\author{
Infant voices: the production of plosives by three-year-olds
}

\author{
Maria Teresa Rosangela Lofredo Bonatto ${ }^{(1)}$
}

\begin{abstract}
RESUMO
Objetivo: apresentar as características fonético-acústicas de produção das consoantes plosivas vozeadas e não-vozeadas por crianças de três anos. Métodos: análise qualitativa baseada na inspeção das características fonético-acústicas de eventos fônicos ocorridos no intervalo de obstrução, na liberação da plosão e na transição para a vogal e análise quantitativa das medidas do Voice Onset Time (VOT), de três repetições das seis consoantes plosivas do Português Brasileiro (PB), por quatro crianças, sendo três meninos e uma menina, falantes nativos do PB, por meio de análise fonético-acústica, em espectrograma de banda larga. Os achados foram comparados com estimativas de valores para a faixa adulta de falante nativo do PB. Resultados: as crianças apresentaram produções semelhantes às que são encontradas na fala adulta, tanto para as plosivas vozeadas como para as não-vozeadas, bilabiais, alveolares e velares. Apresentaram também plosivas vozeadas com interrupção de barra de sonoridade e ocorrência de VOT positivo, e qualidade diferenciada de burst. Para as não-vozeadas, ocorreram a presença da breathy vowel no período de obstrução das plosivas e a presença de aspiração no segmento correspondente ao VOT positivo, para os três pontos de articulação pesquisados. Conclusão: as diferenças encontradas na produção das plosivas vozeadas, quanto às características da barra de sonoridade e qualidade do burst, a presença da breathy vowe/ nas plosivas não-vozeadas e aspiração, caracterizam a produção das plosivas nessa faixa etária. A diversidade das medidas acústicas, verificada pelos valores dos desvios-padrão sugerem que as crianças realizaram diversas tentativas, com diferentes ajustes para produzir tais sons.
\end{abstract}

DESCRITORES: Criança; Fala; Espectrografia; Fonética

\section{INTRODUÇÃO}

O presente trabalho aborda a produção de sons plosivos não-vozeados e vozeados por crianças entre três e três anos e 9 meses (doravante faixa etária de 3 anos). $O$ foco de interesse refere-se às características fonético-acústicas indicativas do contraste de vozeamento, contribuindo para o aprofundamento dos estudos relativos ao desenvolvimento de fala infantil.

(1) Fonoaudióloga; Consultório Maria Teresa Bonatto; Doutoranda em Lingüística Aplicada e Estudos da Linguagem pela Pontifícia Universidade Católica de São Paulo.

Dados integrantes de pesquisa em andamento "Vozes Infantis: A Caracterização do Contraste de Vozeamento das Plosivas do Português Brasileiro na Fala de Crianças de 3 a 12 anos" (LIAAC - PUC-SP) - Auxílio à Pesquisa: Bolsa Capes Flexibilizada.
A inspeção fonético-acústica inicial das consoantes plosivas revela que as crianças da faixa etária de três anos apresentam características na produção da fala que, embora presentes em algumas línguas do mundo ${ }^{1-3}$, não são comuns na fala de adultos, falantes nativos do português brasileiro ${ }^{4}(\mathrm{~PB})$. Essas características de produção de fala sugerem a ocorrência de diferenças na sincronização de gestos em relação à fala de adultos ${ }^{5}$. Tais constatações remontam a fatos da aquisição da linguagem, como as descobertas que as crianças fazem sobre o funcionamento da língua a que estão expostas, e não somente a processos de maturação ou de aspectos relacionados à integridade dos sistemas sensório-motor e perceptual que permitem que a criança faça relação entre os estímulos que ouve e os que produz ${ }^{6}$.

Sabe-se que as consoantes do ponto de vista articulatório podem ser analisadas pelo ponto articulatório como bilabial, labiodental, dental, alveolar, 
alvéolo-palatal, palatal, velar e glotal, pelo modo de articulação como plosiva, nasal, fricativa, africada, tepe, vibrante, retroflexa e laterais e pela atividade laríngea como vozeada e não-vozeada.

No PB, as consoantes plosivas são as bilabiais /p/ e /b/, as alveolares /t/ e /d/ e as velares /k/ e /g/. Na produção desses sons, os articuladores formam uma obstrução total que tem como correlato acústico um intervalo de silêncio, o qual pode ser preenchido por uma barra de sonoridade originada pela vibração das pregas vocais no caso dos segmentos vozeados apontados (/b/, /d/ e /g/). Na seqüência à fase de oclusão, segue-se a liberação repentina da corrente de ar, que ocasiona um ruído, também chamado de burst. O registro acústico correspondente á liberação da corrente de ar refere-se à fonte de ruído transiente ${ }^{2,7-9}$.

Considerando as características de produção de fala de sons plosivos, destacam-se as propriedades acústicas da aspiração, da qualidade do burst, de algumas características fonéticas presentes no intervalo de obstrução, além da medida de duração do Voice Onset Time (VOT), traduzida como tempo de início ou ataque de vozeamento, que corresponde ao intervalo de tempo entre a liberação da oclusão e o início do vozeamento que precede, sucede ou coincide com essa liberação ${ }^{1,7,10}$.

As características acima referidas encontram respaldo na teoria acústica de produção da fala ao considerar o sinal de fala como o resultado de fontes de voz (criadas pela vibração de pregas vocais) e de ruído (criadas pela passagem da corrente de ar pelas constrições formadas pelos articuladores) e do processo de filtragem de tais fontes pelo aparelho fonador. Tais princípios envolvem o modelo fonte-filtro, o qual estabelece relações entre o nível articulatório e fonatório do trato vocal ${ }^{7,8,11}$.

As fontes de ruído geradas no trato vocal podem ser fruto de uma obstrução parcial da corrente de ar, de forma a sustentar o estímulo acústico por um intervalo de tempo (fonte de ruído contínuo), como ocorre com as consoantes fricativas, ou de uma obstrução total da corrente de ar, que liberada provoca o surgimento de um ruído (fonte de ruído transiente), como ocorre nas consoantes plosivas (ou oclusivas), encontradas em todas as línguas do mundo ${ }^{2,9}$.

Outro aspecto a ser observado nas consoantes plosivas vozeadas é que podem apresentar qualidade vocal diferenciada pela atividade laríngea em decorrência da aproximação das pregas vocais, ocasionando características de vozeamento, soprosidade, crepitância ou aspiração ${ }^{2,12}$. Para que ocorra a vibração é necessário que exista equilíbrio entre delicados ajustes laríngeos e mecanismos aerodinâmicos. Dentro dessa classificação, o som consonantal é considerado vozeado quando as pregas vocais estão vibrando (vozeamento este, que pode apresentar-se com crepitância), e não-vozeado quando elas perma- necem separadas. A ocorrência da aspiração devese ao ruído conseqüente da passagem de ar pelas pregas vocais parcialmente fechadas ${ }^{13,14}$.

Há décadas que foneticistas e fonólogos procuram estudar as características articulatórias, acústicas e perceptivas das consoantes plosivas, principalmente quanto ao contraste de vozeamento e aspiração Para adquirir o contraste de vozeamento, além das dificuldades inerentes ao controle da pressão do ar a criança precisa aprender a coordenar o gesto glótico, que ocorre na laringe, ao gesto oral, que ocorre nos articuladores ${ }^{13}$, uma vez que as plosivas nãovozeadas são produzidas com ajustes diferenciados das pregas vocais, que inibe a sua vibração, e os vozeados com elas em atividade vibratória. A sincronização desses ajustes muitas vezes não é a mesma para todas as línguas ${ }^{2,13}$.

Alguns pesquisadores, ao analisarem a fala de crianças com dificuldades na aquisição do sistema fonológico do PB, em decorrência de quadros como: a fala de fissurados, de deficientes auditivos, de disfônicos, entre outros, puderam verificar que a produção das consoantes plosivas vozeadas ocorria com redução da duração da barra de sonoridade, o que colaborava para o julgamento perceptivo-auditivo do som como não-vozeado ou desvozeado ${ }^{15,16}$.

Nas plosivas, a percepção do contraste vozeado/ não-vozeado está associada a vários parâmetros acústicos ${ }^{10}$, dentre eles o VOT. O VOT pode ser classificado como positivo, quando ocorre após a liberação da oclusão e o início do vozeamento da vogal que a sucede; negativo, que corresponde ao intervalo entre o pré-vozeamento e a liberação da oclusão e zero, quando coincide o início do vozeamento com a liberação da oclusão ${ }^{1}$. Os valores de VOT variam de acordo com a língua, o ponto articulatório, a idade, o sexo e a taxa de elocução ${ }^{1,2,7,10}$.

Pesquisa em 18 línguas com o objetivo de verificar a variação do VOT para as plosivas velares, em início de vocábulo, em decorrência da presença de aspiração constatou que esses sons podem ser considerados não-aspirados quando apresentam valores de VOT por volta de $30 \mathrm{~ms}$, levemente aspirados, por volta de $50 \mathrm{~ms}$, aspirados, por volta de $90 \mathrm{~ms}$ e altamente aspirados, por volta de $150 \mathrm{~ms}{ }^{17}$ e propõe que os dados sejam analisados à luz da Fonologia Articulatória (FAR). A FAR foi proposta e desenvolvida pelos teóricos Browman e Goldstein (1986), pesquisadores ligados ao Laboratório Haskins, nos Estados Unidos. A unidade básica dessa Fonologia é o gesto articulatório, caracterização discreta de eventos abstratos, com durações intrínsecas. Esse modelo permite lidar com os aspectos dinâmicos da fala, como a sobreposição de gestos articulatórios e sua sincronização no tempo ${ }^{18}$.

Na fala adulta, a presença de pré-aspiração nas plosivas do norueguês foi considerada um fenômeno 
capaz de permitir a distinção entre as plosivas vozeadas e não-vozeadas, uma vez que na vozeada ocorria a presença de pelo menos $80 \%$ de prévozeamento e na não-vozeada, havia pré-aspiração. Diante de tais achados, a qualidade das plosivas do norueguês pode ser influenciada pela dimensão do gesto de aproximação e vibração ou não das pregas vocais $^{3}$.

Diante da perspectiva acima delineada, o presente estudo apresenta como objetivo investigar as características fonético-acústicas da produção de consoantes plosivas vozeadas e não-vozeadas no PB de crianças na faixa etária de três anos.

\section{MÉTODOS}

A população estudada constou de quatro crianças (referidas como sujeitos 1 a 4) na faixa etária compreendida entre 3 anos e 3 anos e 9 meses, dois representantes do sexo masculino e dois do feminino. Como critérios de inclusão destacam-se a faixa etária entre três e quatro anos, o fato de que todas as crianças eram falantes nativas do $\mathrm{PB}$, nascidas na cidade de São Paulo, sem histórico de bilingüismo. Os critérios de exclusão envolveram nacionalidade estrangeira, tanto no caso das próprias crianças quanto de seus pais, naturalidade de outra cidade que não a cidade de São Paulo, presença de problemas auditivos, cognitivos, motores, fala ou voz, aferidos por meio de triagem fonoaudiológica realizada pela pesquisadora, análise de questionários enviados aos pais e professores e de triagem auditiva realizada por clínica especializada.

O corpus utilizado integra corpora de pesquisa em andamento no Laboratório integrado de Análise Acústica e Cognição (LIAAC) da Pontifícia Universidade Católica de São Paulo (PUC-SP). Foram selecionadas as gravações de quatro crianças que atendiam aos critérios de inclusão expostos, de um total de 125 crianças gravadas e 63 selecionadas para a pesquisa. De cada criança do grupo estudado no presente estudo, foram selecionadas três repetições de seis vocábulos dissílabos, com a estrutura CVCV, em que $C$ representava as consoantes plosivas /p/, /b/, /t/, /d/, /k/ e /g/, e V a vogal /a/, constituindo respectivamente as palavras-chave "papa, baba, tata, dada, caca e gaga", que foram inseridos na frase-veículo "Diga baixinho".

A coleta das referidas amostras de fala foi realizada em escola que as crianças freqüentavam, entidade da rede particular de ensino, situada na zona sul da cidade de São Paulo, o que propiciou a formação de grupo homogêneo em termos sócio-econômicos. As seis frases foram aleatorizadas em três listas diversificadas para o registro de três repetições para cada vocábulo, a partir do estímulo previamente gravado por um sujeito adulto do sexo feminino (a pró- pria pesquisadora), perfazendo um total de 18 frases para cada criança.

No momento da coleta, as crianças sentavam-se à frente de um microfone Shure SM7A posicionado a $15 \mathrm{~cm}$ de distância de seus lábios, ouviam os estímulos através de fones de ouvido, e repetiam as sentenças da mesma forma que ouviam. O computador utilizado foi o Apple Powerbook G4, com o software Pró-Tools, versão 6.2.3. A gravação efetuou-se com apoio de técnico de som especializado e observouse a manutenção da distância entre os lábios da criança e o microfone.

Os estímulos foram digitalizados com uma taxa de amostragem de $22 \mathrm{~Hz}$ analisados no software Praat desenvolvido por Paul Boersma e David Weenink do Departament of Phonetics of University of Amsterdam (disponível no endereço eletrônico: www.praat.org), versão 4.2. Os procedimentos de análise acústica dos dados constaram da inspeção inicial da forma da onda e dos espectrogramas de banda larga e identificação inicial dos segmentos referentes ao trecho compreendido a partir da vogal /i/ da palavra Diga papa baixinho, por exemplo. Na seqüência foram identificados os trechos referentes à oclusão total e liberação da corrente de ar (burst) e à presença ou ausência da barra de sonoridade. Neste momento foram descritas as características referentes a particulares como características do burst e presença de indicativos de aspiração.

Como última etapa, foram extraídos os valores de VOT (em ms), nos traçados de forma da onda, da seguinte maneira:

- para consoantes não-vozeadas: foi extraída a medida de duração do trecho compreendido entre o registro acústico do burst da consoante plosiva (situada na sílaba tônica da palavra-chave) até o início da vogal /a/ da mesma sílaba;

-para consoantes vozeadas: foi extraída a medida de duração do trecho compreendido entre o início da barra de sonoridade da consoante plosiva (situada na sílaba tônica da palavra-chave) até o registro do burst, sendo considerado um resultado negativo, quando a sonoridade aparecesse presente antes do registro do burst e quando este não estava presente foi considerada toda a barra de sonoridade.

As características espectrais de burst e de aspiração foram analisadas do ponto de vista qualitativo, intra e intersujeitos, com base na literatura para achados do PB em adultos ${ }^{4}$ e também foi realizada, por parte da pesquisadora, uma inspeção perceptivoauditiva de cada um dos arquivos de som, o que motivou a realização de um estudo perceptivo, que será relatado em outro artigo, para verificar a influência dessas características no julgamento de adultos ${ }^{19}$. Os resultados das medidas de VOT, da produção da fala das crianças de 3 anos e do adulto, foram analisados estatisticamente com base nos testes ANOVA 
e no Sheffe com nível de significância de $p<0,05$. Neste artigo serão apresentados os valores absolutos relativos às médias (ms) e aos desvios-padrão.

O projeto foi julgado pelo Comitê de Ética da PUCSP, sob o número 019/2007 tendo sido considerado sem risco e com necessidade de consentimento livre e esclarecido.

\section{RESULTADOS}

A análise fonético-acústica revelou que algumas produções das consoantes plosivas pelas crianças apresentaram características compatíveis com as descritas em análise fonético-acústica de sons plosivos na fala adulta, tais como: ausência da barra de sonoridade (VOT positivo) em plosivas bilabiais, alveolares ou velares não-vozeadas e presença de barra de sonoridade (VOT negativo) em plosivas bilabiais, alveolares ou velares vozeadas.

Algumas semelhanças adicionais em relação à produção da fala de adultos referiram-se às características da liberação da oclusão (burst), tais como, a ocorrência de vários bursts (Figura 1a) nas produções das plosivas velares e eventual ausência de burst em plosivas vozeadas (Figura $1 \mathrm{~b}$ ).

Aspectos divergentes às descrições fonético-acústicas do PB na fala do adulto, que foram encontrados nas emissões de todas as crianças, mas não em todas as repetições, referem-se a características de vozeamento (ausência e interrupção da barra de sonoridade), do burst (irregularidades, produção de bursts múltiplos e aumento da sua energia).

A ausência de barra de sonoridade na produção de plosivas bilabiais, alveolares e velares vozeadas ocorreu especialmente fora das palavras-chave das frases-veículo estudadas. Na produção das consoantes plosivas das palavras-chave, o vozeamento mos-

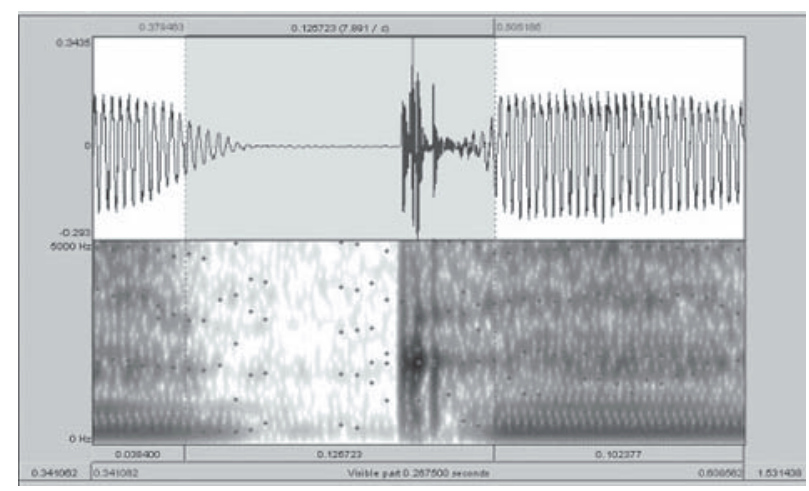

(a) trou-se presente por meio de barra de sonoridade interrompida ou não.

A Interrupção da barra de sonoridade ocorreu nas consoantes plosivas vozeadas para os pontos de articulação bilabiais, alveolares e velares.

As irregularidades na produção do burst foram identificadas enquanto presença bursts múltiplos, registrada em plosivas vozeadas e não-vozeadas bilabiais (Figura 2) e alveolares e ocorrência de aumento de energia nos bursts das plosivas vozeadas e não-vozeadas bilabiais, alveolares e velares, conforme indicado na Figura 3.

Quanto à aspiração, destaca-se o registro de ruído contínuo, na seqüência do registro de burst, conforme ilustrado na Figura 4 e a presença da breathy vowel ao final da vogal, para todas as crianças, no período de oclusão da plosiva não-vozeada (Figura 5).

Outros achados incluíram a produção de fricativas ou aproximantes no lugar de plosivas, em posição acentual pós-tônica na sílaba. Esses dados remetem à dificuldade das crianças realizarem a obstrução total dos articuladores. Também foi constatada a iotização da vogal /a/, em posição acentual tônica, o que propiciou o surgimento de ditongos como em [bayba], [paypa], [kayka], etc.

A comparação entre os valores absolutos das medidas de VOT, apresentadas nas Tabelas 1 e 2, revelou que as plosivas não-vozeadas, em posição acentual tônica e pós-tônica, produzidas pelas crianças de 3 anos possuíam durações mais longas que as do adulto, com exceção do VOT da plosiva /t/, que apresentou valor mais reduzido que o do adulto, mas com grande desvio-padrão. Em relação às vozeadas, em posição acentual tônica e pós-tônica, a comparação revelou que as crianças seguiram o padrão adulto, ou seja, as bilabiais com valores maiores que as alveolares e estas maiores que as velares, porém todas essas plosivas apresentaram desvios-padrão altos.

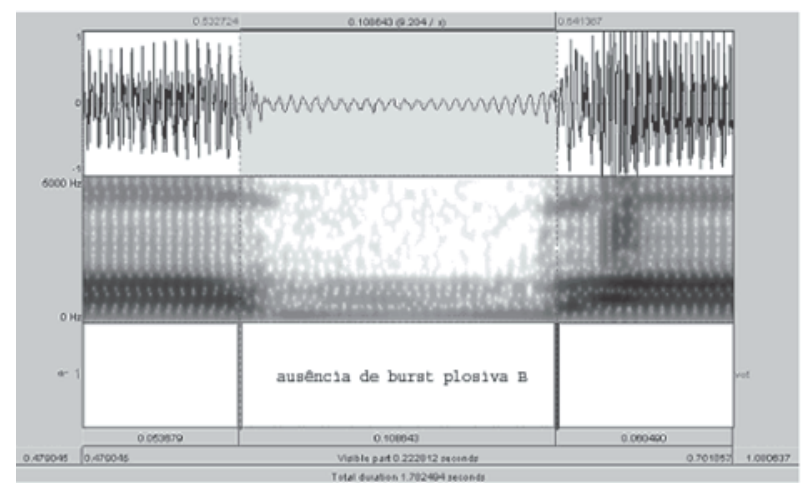

(b)

Figura 1 - (a) Exemplo de registro acústico de burst em plosiva não-vozeada velar /k/ em caca produzida por criança do sexo masculino de 3 anos (b) ausência de burst em plosiva vozeada bilabial /b/ em baba produzida por criança do sexo masculino de 3 anos e 9 meses 


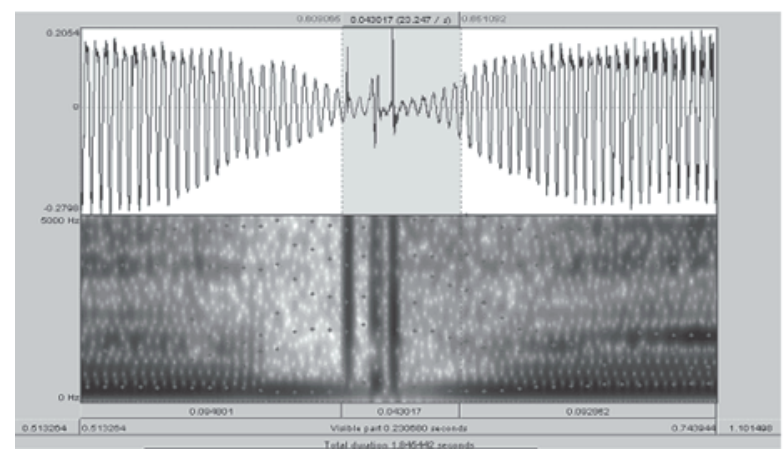

Figura 2 - Exemplo de bursts múltiplos da plosiva bilabial não vozeada |p| em posição acentual póstônica por uma criança do sexo masculino de 3 anos de idade

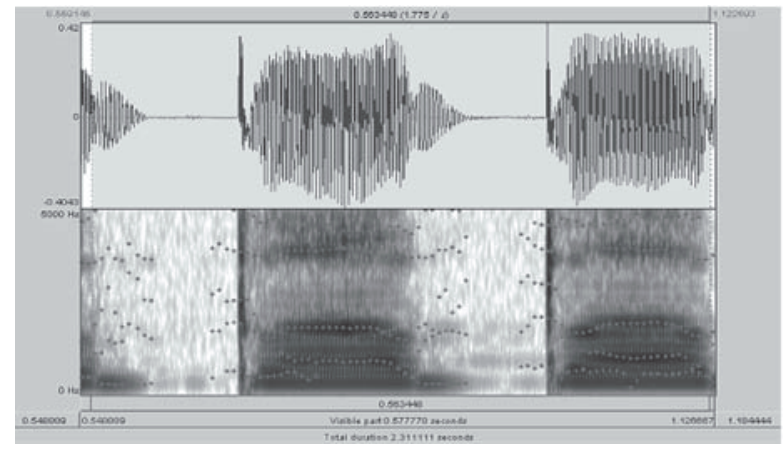

Figura 3 - Exemplo que mostra aumento da energia espectral de burst das plosivas bilabiais /b/ em baba por uma criança do sexo masculino de 3 anos de idade

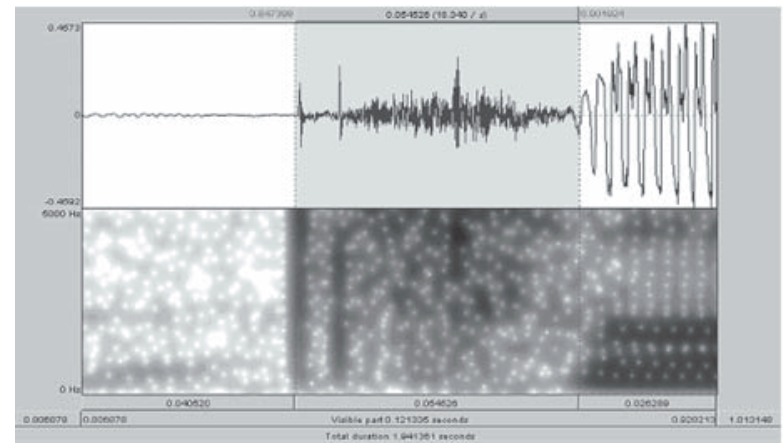

Figura 4 - Exemplo que mostra a ocorrência de aspiração em plosiva alveolar não-vozeada em posição acentual pós-tônica, na palavra tata, produzida por uma criança do sexo masculino de 3 anos e 9 meses

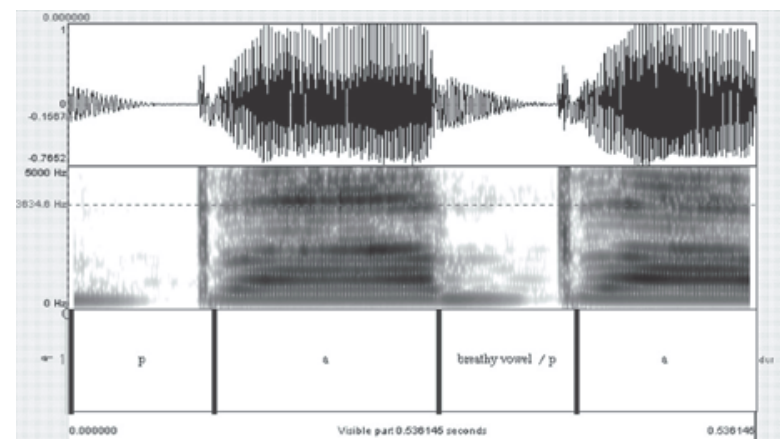

Figura 5 - Exemplo que mostra a ocorrência de fonação breathy, em posição acentual pós-tônica, na palavra "papa" produzida por uma criança do sexo masculino de 3 anos 
Tabela 1 - Medidas de VOT das plosivas nãovozeadas e vozeadas, em posição acentual tônica, com média (ms) e desvio-padrão

\begin{tabular}{ccc}
\hline VOT(ms) & 3anos & adulto \\
\hline$/ \mathrm{p} /$ & $35(48)$ & $10(1)$ \\
$/ \mathrm{t} /$ & $11(35)$ & $19(1)$ \\
$/ \mathrm{k} /$ & $37(15)$ & $29(1)$ \\
$\mathrm{lb} /$ & $-95(22)$ & $-57(2)$ \\
$/ \mathrm{d} /$ & $-88(20)$ & $-56(3)$ \\
$/ \mathrm{g} /$ & $-67(76)$ & $-50(3)$ \\
\hline
\end{tabular}

Tabela 2 - Medidas de VOT das plosivas nãovozeadas e vozeadas, em posição acentual póstônica, com média (ms) e desvio-padrão

\begin{tabular}{ccc}
\hline VOT(ms) & 3anos & adulto \\
\hline$/ \mathrm{p} /$ & $35(48)$ & $10(1)$ \\
$/ \mathrm{t} /$ & $11(35)$ & $19(1)$ \\
$/ \mathrm{k} /$ & $37(15)$ & $29(1)$ \\
$/ \mathrm{b} /$ & $-95(22)$ & $-57(2)$ \\
$/ \mathrm{d} /$ & $-88(20)$ & $-56(3)$ \\
$/ \mathrm{g} /$ & $-67(76)$ & $-50(3)$ \\
\hline
\end{tabular}

\section{DISCUSSÃO}

A análise acústica dos dados comprovou que existe uma variabilidade muito grande na produção de fala de crianças de 3 anos, quando comparada com a do adulto e que pode ser decorrente da falta de precisão fonética que fica evidenciada pelo aumento do desvio-padrão nas medidas dos parâmetros acústicos obtidos para a fala infantil $7,20,21$.

Em segmentos correspondentes às consoantes plosivas não-vozeadas, foi encontrada a ausência de barra de sonoridade, característica que geralmente é qualificada na análise acústica como VOT positivo. De forma similar, a presença de barra de sonoridade em todo o período de oclusão de segmentos correspondentes às plosivas vozeadas ilustra a ocorrência de VOT negativo (produção do vozeamento antes do burst da oclusão). Tais achados encontram-se em concordância com achados da fala adulta sem distúrbios.

Em outros momentos, entretanto, foram encontrados registros que fogem à descrição do $\mathrm{PB}$, como a interrupção da barra de sonoridade e presença de VOT positivo, em segmentos que correspondem às plosivas vozeadas, possivelmente porque as crianças não tivessem conseguido permanecer com o ajuste adequado para manter as pregas vocais vibrando, apesar de conhecerem o padrão da língua ${ }^{13,15,16}$.
Como foi realizada uma prévia inspeção perceptivoauditiva nos arquivos de som, foi possível perceber que consoantes plosivas vozeadas eram percebidas como vozeadas, quando estavam inseridas na fraseveículo, porém quando ouvidas apenas na palavrachave ou na sílaba, pareciam não-vozeadas. Foram comparadas com os espectrogramas e verificou-se que nos segmentos relativos às plosivas havia interrupção de barra de sonoridade o que apontava para a importância da análise acústica na compreensão da fala das crianças, levando à elaboração de um teste de percepção, que estará descrito em outro artigo, e que permitiu verificar como os fenômenos de vozeamento são percebidos pelo adulto. $\mathrm{O}$ que foi possível afirmar, pelos dados obtidos, é que as crianças da pesquisa já apresentavam a distinção do vozeamento desde os 3 anos ${ }^{22-24}$.

Na produção das plosivas não-vozeadas ocorre um aumento da pressão intra-oral atrás do ponto de obstrução que, quando liberado provoca um burst que pode facilmente ser localizado na forma da onda e no espectrograma de banda larga. Os sons plosivos articulados nas proximidades das pregas vocais como no caso das velares têm acusticamente um VOT mais longo ${ }^{7}$. Nos dados da fala infantil nesse trabalho, constatou-se maior duração do VOT nas velares e menor diferenciação do que na fala adulta entre os valores de VOT bilabial e velar. Também se verificaram diferenças na evolução da duração ao comparar a fala infantil e adulta em relação ao ponto de articulação alveolar com os demais. As plosivas bilabiais não-vozeadas seguidas da vogal /a/, na fala infantil, mostraram valores de VOT mais próximos das velares do que os verificados em estudos da fala adulta. Tal diferenciação pode ser interpretada, à luz de pressupostos da Fonologia Articulatória, como decorrentes de dificuldades em sincronizar articuladores diferenciados, no caso referido aqui: os lábios e o dorso da língua.

Na liberação da oclusão, geralmente ocorre a presença de um ruído transiente, denominado burst, pista acústica robusta que está vinculada ao contraste de vozeamento ${ }^{1,10}$. Para que ocorra o burst é necessário um ajuste preciso e capaz de deslocar a massa de ar que está na frente da obstrução para que o fluxo aéreo passe pelo trato vocal ${ }^{17}$. Tal pista acústica, burst, revelou-se nos espectrogramas das crianças com aumento de energia ou em ocorrências múltiplas, diferentemente da fala do adulto, o que leva a considerar um padrão de produção diferenciado da fala do adulto. Deve-se recordar que tais crianças não apresentavam distúrbios de fala.

A ocorrência da aspiração deve-se ao ruído conseqüente da passagem de ar pelas pregas vocais parcialmente fechadas, sendo utilizada em algumas línguas, como o inglês, para diferenciar a produção das plosivas vozeadas e das não-vozeadas, com e sem aspiração 
2,3,20-22, mas não no PB. No presente estudo, algumas crianças apresentaram fonação breathy no final da vogal tônica durante o intervalo correspondente à obstrução que precedia a consoante pós-tônica, que é característica de algumas línguas, como o norueguês ${ }^{3}$, mas não no PB. Da mesma forma, segmentos correspondentes às plosivas não-vozeadas apresentaram aspiração ${ }^{2,17}$, que também não é característica no $P B$, mas que pode ser decorrente da manutenção da abertura das pregas vocais por parte das crianças, por um tempo mais prolongado.

O fato de ocorrer a produção de fricativas ou aproximantes, em lugar de plosivas apenas na sílaba pós-tônica, sugere que a criança ainda tem dificuldades em implementar tal padrão acentual na língua ${ }^{13}$.

Um outro fenômeno constatado a partir dos espectrogramas de banda larga foi a "iotização" da vogal /a/ em posição acentual tônica, [bay ba], [pay pa], [kay ka] que propiciou o surgimento da ditongação. Em termos articulatórios pode-se pensar que a criança movimentou lentamente a língua ${ }^{5}$, já se preparando para produzir o vocábulo seguinte ("baixinho"). Essa movimentação pode desencadear a "iotização" ao passar pelo palato duro numa velocidade um pouco superior à de uma semivogal.

\section{CONCLUSÃO}

A natureza dos resultados ressalta a relevância da exploração fonético-acústica da produção das plosivas por crianças, uma vez que permitem evidenciar estratégias e dificuldades na realização de gestos e em sua sincronização e considerar efeitos destes na percepção da fala. A presença produtiva da aspiração que não é característica distintiva do PB, na produção de consoantes plosivas não-vozeadas, sugere dificuldades na sincronização entre o gesto glotal e o articulatório.

O trabalho mostrou também que a análise acústica pode tornar-se um instrumento importante principalmente em áreas de reabilitação como na Fonoaudiologia, no que diz respeito à compreensão da produção de fala de crianças, oferecendo subsídios a clinica.

\begin{abstract}
Purpose: to present the phonetic-acoustic features of the production of both voiced and voiceless plosives by three-year-old children. Methods: qualitative analysis based on the inspection of phoneticacoustic characteristics of phonic events occurring in the obstruction interval, in the burst, and in the transition to the vowel as well as quantitative analysis of the measures of the voice onset time (VOT), of three repetitions of the six plosive consonants of Brazilian Portuguese (BP) by four native-speaker children in the three-year-old age bracket, three boys and one girl, by means of an acoustic-phonetic analysis, in a wide-band spectrogram. The findings were compared to estimates of values for the adult group of native speakers of Brazilian Portuguese (BP). Results: the children showed production of plosives with VOT similar to that of adult speech both for voiced and unvoiced plosives, bilabials, alveolars and velars. They also showed productions dissimilar to adults, such as voiced plosives with interruption of the voice bar and positive VOT, besides a particular quality of burst. As regards the unvoiced plosives, there were episodes of breathy vowel during obstruction as well as of aspiration in the segment corresponding to positive VOT, in the three articulation points under study. Conclusion: differences found in the production of voiced plosives as regards spectral features of the voice bar and burst quality as well as the occurrence of breathy vowel in unvoiced plosives along with aspiration, characterize the production of plosives in this age bracket. The diversity of acoustic measures, observed by the values of shunting line-standards, suggest that children made several attempts, with various degrees of adjustment, to produce such sounds.
\end{abstract}

KEYWORDS: Child; Speech; Spectrography; Phonetics

\section{REFERÊNCIAS}

1. Lisker L, Abramson A. A cross language study of voicing in initial stops: acoustical measurements. Word J Linguistic Circle. 1964; 20(3):384-422.

2. Ladefoged P, Maddieson I. The sound's of the world's languages. Massachusetts: Blackwell; 1996. p. 47-101.
3. Dommelen WA. Preaspiration in intervocalic $|\mathrm{k}| \mathrm{x}|\mathrm{g}|$ in nowergian. San Francisco: IPCphs; 1999. p. 2037-40.

4. Behlau MS. Análise do tempo de início da sonorização na discriminação dos sons plosivos do português. [doutorado]. São Paulo (SP): Escola Paulista de Medicina; 1986.

5. Albano EC. O gesto e suas bordas: esboço da fonologia acústico-articulatória do português brasilei- 
ro. Campinas: Mercado de Letras e Associação de Leitura do Brasil; FAPESP; 2001.

6. Albano EC. Da fala à linguagem tocando de ouvido. 1. ed. São Paulo: Martins Fontes; 1990.

7. Kent RD, Read C. The acoustic analysis of speech. San Diego: Singular Publishing Group; 1992.

8. Matheus MHM, Andrada A, Viana MC, Villalva A. Fonética, fonologia e morfologia do português. Lisboa: Universidade Aberta; 1990.

9. Maia ECM. No reino da fala: a linguagem e seus sons. São Paulo: Ática; 1985.

10. Shimizu K. A cross: language study of voicing contrasts of stop consonants in asian languages. Tokyo: Seibido; 1996.

11. Fant G. Acoustics theory of speech production month. Hague; 1960.

12. Laver J. Principles of phonetics. Cambridge: Cambridge University Press; 1994.

13. Kenstowizc M. Phonology in generative grammar. 1. ed. Cambridge: Blackwell Publishers; 1994.

14. Aronson AE. Clinical voice disorders: an interdisciplinary approach. 3. ed. New York: Thieme INC; 1990.

15. Levy IP. Uma nova face da nau dos insensatos: a dificuldade de vozear obstruíntes em crianças de idade escolar. [doutorado]. Campinas (SP): Universidade Estadual de Campinas; 1993.

16. Brito AT. Análise fonético-fonológica do estudo do vozeamento, desvozeamento e não-vozeamento na fala infantil normal e com desvios. [mestrado]. Belo Horizon- te (MG): Universidade Federal de Minas Gerais; 2000. 17. Cho T, Ladefoged P. Variation and universal in VOT: evidence from 18 languages. J Phonetics. 1999; 27:207-29.

18. Browman CP, Goldstein L. Articulatory phonology: an overview. Phonetica. 1992; 49:155-80.

19. Veloso J. The role of consonantal duration and tenseness in the perception of voicing distinctions of portuguese stops. XIII International Congress of Phonetic Science. Stockholm: Stockholm Proceding - IPChs; 1995. p. 266-9.

20. Koenig LL. Distributional characteristics of VOT in children's voiceless aspirated stops and interpretation of developmental trends. J Speech, Lang Hear Res. 2001; 44(5):1058-68.

21. Kent RD, Forner LL. Speech segment duration in sentence recitations by children and adults. J Phonetics. 1980; (8):157-68.

22. Macken MA, Barton D. The acquisition of the voicing contrast in english: a study of voice onset time in word: initial stops consonants. J Child Lang. 1980; 7(1):41-74.

23. Davis K. Phonetic and phonological contrasts in the acquisition of voicing: voice onset time production in hindi and english. J Child Lang. 1995; 22(2):275305.

24. Larrañaga $P$, Lleó $C$, Prinz M. A cross linguistic VOT analysis of early stops production: the development of the feature voicing. ICPhs Stockholm. 1995; (3):440-3.
RECEBIDO EM: 14/11/2006

ACEITO EM: 14/05/2007

Endereço para correspondência:

Av. Paulista $509,4^{\circ}$ andar conj. 410

São Paulo - SP

CEP: $01311-910$

Tel.: (11) 32889216 / Fax: (11) 32625344.

E-mail: mteresabonatto@uol.com.br. 